Chapter 23

\title{
Underutilized Crops and Intercrops in Crop Rotation as Factors for Increasing Biodiversity on Fields
}

\author{
Franc Bavec and Martina Bavec \\ Additional information is available at the end of the chapter \\ http://dx.doi.org/10.5772/59131
}

\section{Introduction}

Protection of biodiversity in intensive agricultural areas was one of the priorities of Common Agricultural Policy (CAP) and Agri-environmental payment (AEP 2007-2013) [1]. In general, AEP measures include crop rotation, the greening of fields, organic agriculture, soil coverage in water protected areas, etc., which depend on detailed national measures. In the new EU perspective of the Greening CAP reform 2014-2020 [2], three basic measures are foreseen in the first pillar: (i) maintaining permanent grassland; and (ii) crop diversification (a farmer must cultivate at least 2 crops when his arable land exceeds 10 hectares and at least 3 crops when his arable land exceeds 30 hectares. The main crop may cover at most $75 \%$ of arable land, and the two main crops at most $95 \%$ of the arable area); (iii) maintaining an "ecological focus area" of at least $5 \%$ of the arable area of the holding for farms with an area larger than 15 hectares (excluding permanent grassland) - i.e. field margins, hedges, trees, fallow land, landscape features, biotopes, buffer strips, afforested area. This figure will rise to $7 \%$ in 2017 according to the Commission report and the legislative proposal (CAP reform [2], MEMO 13/621, 26.6.2013). In the $2^{\text {nd }}$ pillar documents (Regulation EU 1305/2013, 17.12.2013), 'biodiversity' is mentioned 12 times and is mainly focused on conversion into organic farming, the protection of biodiversity in Nature 2000 areas and forest biodiversity conservation statuses of species and habitats, as well as enhancing the public amenity value of Nature 2000 areas or other high value nature areas. In these documents, we were mainly faced with general terms of biodiversity, however the detailed measures in the second pillar should be defined on a national level. There is also the EU Biodiversity Strategy to 2020, which is trying to halt the loss of biodiversity and the degradation of ecosystem services in the EU by 2020 . It is also trying to feasibly restore biodiversity, while stepping up the EU contribution to averting global biodiversity loss. In case of pollinators and their vs. pollinators' plants, they are mentioned 
only in introduction of document. In the agricultural part the focus is only on maximising agricultural areas across grasslands, arable land and permanent crops that are covered by biodiversity-related measures under the CAP so as to ensure the conservation of biodiversity and to bring about a measurable improvement in the conservation status of species and habitats affected by agriculture and in the provision of ecosystem services as compared to the EU 2010 Baseline, thus contributing to enhance sustainable management; without mentioned intercrops and diverse - alternative crops.

\section{Aim and methodology}

The Biodiversity Strategy to 2020, compared to previous documents, places more emphasis on field crop areas, but the measurements for 55.9 mio ha of field crop areas in Europe (FAO stat, 2012) are still not defined clearly enough, which is why special measurements for increasing the biodiversity of crops are needed on the intensive fields. As we can see in the Greening CAP reform 2014-2020 [2], these actions manage only a small portion of the $2^{\text {nd }}$ and/or $3^{\text {rd }}$ crop, and all of those can be produced in monoculture. Further on, the $1^{\text {st }}$ Pillar supports more green washing than actual change of crop rotation, crop structure and diversity of field crops on the fields. Pillar 2, which depends on national regulations and is more open to potentially important measurements (like intercropping and introduction of alternative - rare - underutilized crops into field crop production for increasing biodiversity) is rarely mentioned in regulations and strategies. Sometimes its importance is unknown to administration workers, which is probably the reason why officers are not interested in their implementation (a good example is the Slovenian Ministry for Agriculture and Environment). A review of relevant literature, research and practical experiences of the authors will be present in this chapter.

\section{Crop rotation}

It is a fact that intensive agriculture and dominant monoculture based on high chemical inputs and even genetically modified organisms in some countries are destroying the fields biodiversity. The decreasing soil biodiversity does not support the natural cycles for sustaining good soil characteristics and natural plant nutrition pathways. For those in the system, like the US Corn Belt where these issues are key environmental problems include water contamination by nutrients and herbicides emitted from cropland, a lack of non-agricultural habitat to support diverse communities of native plants and animals and a high level of dependence on petrochemical energy in the dominant cropping systems. In addition, projected changes in this region's climate, which include increases in the proportion of precipitation coming from extreme events, could make soil and water conservation in existing cropping systems more difficult [3]. In spite of the professionals' scepticisms about intensive systems, the authors Liebman et al. [3] concluded that increasing biodiversity through the strategic integration of perennial plant species can be a viable strategy for reducing the reliance on purchased inputs and for increasing agro ecosystem health and resilience in the US Corn Belt. It is our concern 
that the measures in the EU Greening CAP reform 2014-2020 in the first pillar will not solve these kinds of problems in European countries either.

Biodiversity and plant protection against plant diseases and pests research is becoming an important issue in the world. For example, crop diseases are the most important natural disasters for food production and food safety, they are also one of the main reasons confining sustainable development of agricultural production. The discovery of the biodiversity mechanism (instead of chemicals and genetic modified organisms) to control crop diseases can reasonably guide the rational deployment and rotation of different crops and establish an optimization of different crop combinations [4].

The transformation of agriculture in the past half-century has triggered a decline in bees and other insect pollinators. In this case it is concluded [5] that areas of cultivated land farming, field margins, field edges and paths, headlands, fence-lines, rights of way, and nearby uncultivated patches of land are important refuges for many pollinators. According to the authors of this chapter, the yield of buckwheat increased twice in cases of pollination by honey bees compared to isolated plants by covering plots without honey bees (not published data). Likewise, crops including at least 800 cultivated plants depend on animal pollination in a functional biodiversity, which can be increased by intercrops and more diverse crop species in crop rotation. These solutions were not clearly defined and supported by professionals and policy makers, not even in the EU CAP reform and at the country levels as separate measures in Pillar 2 (like in Slovenia).

\section{Biodiversity and the multifunctional importance of alternative field crops $^{1}$}

Intensive agriculture based on monoculture evidently reduces fields' biodiversity (Fig. 1) including the number of utilized crops and in consequence reduces natural health and nutritional compounds in the food. As reported by Jacobsen et al. [6], we have to safeguard both biodiversity and arable land for future agricultural food production, and we need to protect genetic diversity to safeguard ecosystem resilience. They conclude that majority of the research funding currently available for the development of genetically modified crops would be much better spent in other research areas of plant science, e.g., nutrition, policy research, governance, and solutions close to local market conditions if the goal is to provide sufficient food for the world's growing population in a sustainable way.

Introduction of alternative (rare, underutilized, disregarded, neglected, new and alternative GMO free) crops into the structure of field crop rotation can increase plant biodiversity and the nutritional and health value of food. Alternative crops are rich natural resources of essential amino acids, antioxidants, minerals, stimulators and other usable compounds, which are often limited to products from just a few main crops produced over the world. Production of

1 The section based on research of Bavec F. presented in the Agrosym 2011 paper, which content is republished with permission. 


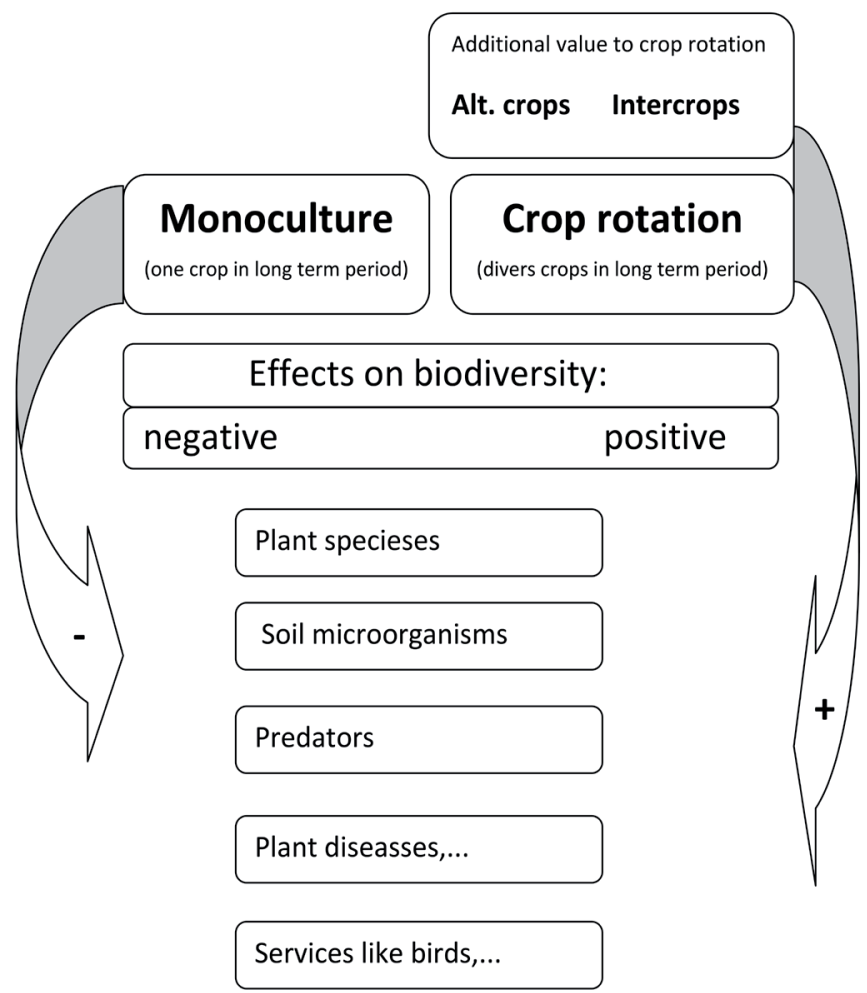

Figure 1. Comparison of negative effects of monoculture and positive effects of crop rotation, alternative crops and intercrops on biodiversity parameters

underutilized crops shall help to increase resistance to plant diseases, predators, and helping us to produce food without synthetic pesticides [7]. The described organic production of underutilized field crops represents a very important option for an environmentally acceptable crop production and a niche for 'special organic' products. The selling of this kind of products is of special interest for small scale farms, because it is a better solution compared to producing and selling cheaper products on global markets. But in this case the consumers, advisers and farmers need professional knowledge about the preferences of underutilized crops, production characteristics, clear guidelines for organic production, post-harvest technology, food processing including product certification and clear marketing strategies. The support given by educational, research and governmental institutions should also be in accordance with these needs. Each specific possibility and activity of each country can influence the consumerproducer relationships and the effective marketing by specific or/and niche products based on underutilized crops $[8,9]$. 
A rich biodiversity of produced edible underutilized field crops encompasses cereals and pseudo cereals including millets, pulse crops, root and tuber crops, oil seed crops and dyes, some of which (including fibre crops) are usable for creating new market niches based on small scale production and processing. Furthermore, some of them are also suitable for industrial processing. Depending on the country, some of these plants are indigenous, and based on spread secondary diversity, some are completely new, sometimes even exotic. The understanding and use of underutilized crops is based mainly on tradition and the specifics of their growth circumstances. Most of them are unknown to a great percentage of agronomists. But the interest for underutilized crops is also increasing with publishers, because during the last decades a few publications spread the knowledge about underutilized field crops [10, 11, 12] with a special attention to temperate climate [7].

For example, in Slovenia temperate climate circumstances are predominant and just a small part is Mediterranean. For those, the tropic crops should be introduced into the temperate climate with special attention to a growth period of less than 160 frost free days, such as those for genotypes of sweet corn (Zea mays L. var. saccharata), batata (Ipomea batata L.) and other tropical tuber crops, specific genotypes of grain amaranths (Amaranthus sp.), quinoa (Chenopodium quinoa L.), groundnut (Arachis hypogea L.), vignas (Vigna ssp.), etc. The next factor is the system of reproduction based on plant parts growth in greenhouse conditions during winter time like in the case of batata. The spelt which is well adapted to temperate climates (Triticum aestivum L. ssp. spelta MacKey) has been forgotten, however todays introduced into crop rotations on many organic farms with field crop production during the last decade. Other farro group cereals such as einkorn (Tritium monocccum L.), emmer (Triticumdicoccum L.), etc. are introduced into organic farming just like sample crops on a few farms. Buckwheat (Fagopyrum esculentum L.), proso millet (Panicum milliaceum L.) and oil seed pumpkins (Cucurbita pepo L. group Pepo) were traditional, but neglected until the last decade when their production started to increase. The group of alternative oil crops such as false flax (Camelina sativa L.), saflower (Carthamus tinctorius L.), garden poppy (Papaver somniferum L. ssp. somniferum Kadereit) are being researched and considered for eventual introduction into crop rotations. We are also looking at some legumes and the group of millets from Africa-potential crops for dry conditions described in the book Organic production and use of alternative crops by Bavec and Bavec [7]. In changing climate conditions some crops like millets from Africa and quinoa from the Andes might play an important role for creating new stress-tolerant species and genotypes for future agriculture. However, quinoa is described as a crop with high biodiversity value, which maintains productivity even on rather poor soils and high salinity [13].

Traditional cropping systems of undeveloped countries contain numerous genotypes of domesticated crop species, as well as their wild relatives. The richness of plant biodiversity of traditional agro-ecosystems is comparable with natural systems. It is one of the reasons why underutilized crops have to play a greater role, especially in organic farming. Underutilized crops bring diversity into crop rotations and provide new possibilities for soil cultivation. Organic farming, which is based on traditional farming systems, offers a way of promoting the diverse food and food risks, it increases pollinator insects and reduces plant insects and disease incidence, it is efficient in labour use and it also brings an intensification of production 
with acceptable resources, a maximization of returns and stability under responsible technologies. Underutilized crops help local communities to be more independent while using the local resources for production and transport expense reduction. A similar option might be used for organically produced underutilized crops [14]. The use of underutilized field crops has resulted in an in ceased product competitiveness, a rich nutritional and health value of food, in tradition, locality, special quality according to organic production guidelines and even in market attractions. The health and nutritional rich products, especially if they are produced according to organic farming guidelines, represent a special niche in the market of the developed world.

Knowledge about food health and nutritional attributes based on underutilized crops is very useful for promotion, decision support for producers and for the buying motivation of consumers. Special attention needs to be given to the coexistence of pollinator insects and buckwheat, to antioxidants in food (tocopherols in oil crops, squalen in grain amaranths, anthocyanins in sweet potato, etc.), to rich amino acid compositions (grain amaranths, quinoa, partly buckwheat, partly legumes, etc.), to gluten free foods for people with celiac disease (buckwheat, grain amaranth, quinoa, millets), to good quality fibre food (whole grained spelt and other cereals), to food rich in minerals, vitamins and their good balance, etc. Many of them are used in pharmacology and alternative medicine, like oil seed pumpkins [15], buckwheat $[16,17,18]$, amaranths $[19,20]$, etc.

The above information show a very interdisciplinary approach to alternative field crops, which can help to change the structure of crop diversity with clear steps towards a better social and economic behaviour. At the field level the rich crop diversity supports multifunctional processes like more sustainable nutrient cycles, caused by different root systems and different nutrient uptakes. A bigger variety of crops in crop rotation leads to more permanent soil covers of plants during growth periods, especially if they are grown in stubble crops. If some of them are grown as green manure they can have an important influence on soil fertility, because of more rich micro-organisms activity. In cases such as Brasicaceaes, for example white mustard (Sinapis alba), the crop also has a phytosanitary effect. Diverse crops encourage more sustainable production systems because of the positive effects on relationships between predators and pests (Fig. 1). They also decrease plant diseases in crop rotation, because of their life cycle breaks.

\section{Intercropping - Unexploited beneficial measure ${ }^{2}$}

Intercropping (sowing two or more crops together) represents a high valued strategy for long term sustainable plant production management, due to its many beneficial effects like effects on increasing diversity of cultivated crops, nitrogen fixations by legumes $[21,22,23,24]$ instead of synthetic $\mathrm{N}$ fertilisers, weed control, yield stability, inter-specific complementarity, a more efficient use of environmental sources, soil coverage in under-sown crops, a higher protein

2 The section based on research of Bavec F. presented in the Agrosym 2011 paper, which content is republished with permission. 
content in seeds used for grain feed or silage mixture (especially important after BSE crises, etc.). Because of the complexity of these systems, intercropping has been neglected in practice and just partly researched as a plant production system under climates and cultivation circumstances worldwide. The research is deficient, especially in the case of intercropping impacts on biodiversity [25].

Farmers and researchers carry out different cropping systems to increase productivity and sustainability by using crop rotations, relay cropping, and intercropping of different annual crops. An associated culture often involves cereals and legumes due to its advantages for soil conservation, weed control, lodging resistance, yield increment, hay curing, forage preservation over pure legumes, high crude protein content and protein yield. Different seeding ratios or planting patterns have been practised for cereal-legume intercropping. Bean yields in an intercrop culture are usually less sown than those obtained from sole bean stands. It is possible to increase yields with suitable management practices such as the use of optimum plant population and improved bean cultivars. However, bean yields in intercrops represent a surplus to the main maize crop yield. In EU countries, cowpea is rarely used in intercropping with cereals on small-scale farms. A number of indices such as land equivalent ratio, relative value total and monetary advantage have been proposed to describe the competition within and economic advantages of intercropping systems (from unpublished review, Bavec et al., Univ. Maribor). However, such indices have not been used for climbing bean (Phaseolus vulgaris L.) and maize intercropping to evaluate the competition among species and to evaluate the economic advantages of each intercropping system.

Intercropping of climbing bean and maize is a common production system on small scale farms and of interest to researchers in Latin America, as well as in South Africa, Ethiopia and other African countries. In a temperate climate, this type of intercropping has traditionally been practised 30 years ago, also on small-scale farms in Slovenia, Romania and in other Middle and Eastern European countries. Despite the fact that intercropping systems should involve integrating crops, using space and labour more efficiently, recommendations supporting good sole cropping systems, in which net incomes are also higher.

In Slovenia, two cases of conversion from a manual to mechanized production system of intercropped bean and maize production was established on an approximate 4 to 6 ha planting area per year, where the bean seeds are used for silage fed to ruminants (farm Jankovič, Vihre/ Krško), and for human consumption (farm Jakob, Lipovci). In the other European countries we also practically lost this traditional production system, although it still exists in some poor and self-sufficient small-scale farms, with some attention on the dry climate due to recent climate changes [26].

In general, important benefits of intercropping cereals with legumes are the following: more available nitrogen due to nitrogen fixation with legumes-with up to $84 \%$ of nitrogen may be derived from fixation by the climbing bean, maize and bean intercropping may help converse a deficiency of bean production in European countries, in that it involves integrating crops using space and labour more efficiently, increased efficient competitions of cereals with weeds, improved soil structure, reduced loss of plant nutrients, less damage of plants due to pathogens and insects, especially in organic farming systems. Based on the available literature, most 
researches have focused on intercropping bush beans in non-European growing conditions. Because of the different canopy characteristics of bush beans, data for bush beans are not comparable with climbing bean maize intercropping - this has only been reported by Gebeyehu et al. [27]. However, there is a lack of scientifically relevant information about promising plant ratios of maize-climbing bean intercropping systems, especially for the ones produced in European temperate zones under integrated or organic production systems.

In this paper we want to focus our attention on two additional reasons for the proposed intercropping climbing bean/maize in temperate climate vs. marginal regions for maize (to FAO group 400) production [28], which are also suitable for growing climbing beans, due to temperatures and humidity, enabling a simple and environmentally friendly production. In this case the soil preparation is conventional (ploughing in autumn, pre-sowing soil preparation in spring), the same machine is used for sowing maize and bean seeds. The bean seeds need to be sown close to the maize strips at the stage when the maize has few true leaves, after the $1^{\text {st }}$ or $2^{\text {nd }}$ inter-row mechanical hoeing, close to the strips of the maize plants. For harvesting the maize bean whole plant mixture a silage combine is used, but for the seed harvesting a cereal combine and eventual separation of the bean and maize seeds could take place. The second benefit is the production of protein rich silage caused by bean grains, which contain approximately $20 \%$ of crude proteins. These kinds of proteins are good and might be a relatively cheap replacement for animal source proteins, which are not allowed for ruminants feed after the appearance of BSE 'mad cow disease'.

In cereal-legume intercropping, cereal crops establish uniform canopy structures and then legume crops and the roots of cereal crops grow to a greater depth than those of legume crops with less lodging consequences [29]; however the agronomic traits of genotypes need to be well adapted for intercropping. Climbing bean cultivars need specific adaptations to intercrops using predominantly morphological maize types grown in the area [27]. Somewhat earlier maize cultivars can give an improved net income when intercropped with climbing beans, because they are resistant to stem lodging. This indicates that the component crops probably have differing spatial and temporal use of environmental resources such as radiation, water and nutrients. Therefore, this cropping system may help improve productivity of low external input farming, which depends largely on natural resources such as rainfall and soil fertility. The intercropping productivity is largely dependent on planting date and plant population of its components. Small-scale farmers have practised traditional cropping techniques, such as intercropping, in which they unknowingly manipulate the plant population [28] because that way, interspecies competition is stronger.

The effects of intercrops on weed communities were characterised in terms of growth, species diversity (richness and evenness), and floristic and functional composition. Intercrops and barley monocultures generally produced similar effects on the companion weed communities, whereas pea effects were less suppressive and more variable. Spring-emerging species generally increased its relative importance in the intercrop weed communities; whereas winter-emerging species were usually less abundant in intercrops. Divergence in the abundance of winter and summer emerging weeds could be attributed to the different canopy dynamics of intercrops and monocultures [30]. 
Plant diversity based on intercropping systems includes potentially important mechanism for chemically mobilizing nutrients in otherwise-unavailable forms of one or more limiting soil nutrients, such as phosphorus $(\mathrm{P})$ and micronutrients (iron (Fe), zinc ( $\mathrm{Zn}$ ) and manganese $(\mathrm{Mn})$ ). In case of phosphorus-mobilizing, crop species improve P nutrition for themselves and neighbouring non-P-mobilizing species by releasing acid phosphatases, protons and/or carboxylates into the rhizosphere which increases the concentration of soluble inorganic $\mathrm{P}$ in soil. Similarly, on calcareous soils with a very low availability of Fe and Zn, Fe-and Znmobilizing species, such as graminaceous monocotyledonous and cluster-rooted species, benefit themselves, and also reduce Fe or Zn deficiency in neighbouring species, by releasing chelating substances [31].

Only in one EU research programme a survey was carried out within five European countries with regard to the practice of cereal grain legume intercropping. The most commonly used combination was spring barley-spring pea with 27 other combinations between pulses and cereals. $72 \%$ of all examples consisted of spring varieties and the rest of winter varieties, mainly a special case of the French South West with a mild winter climate. Intercrops were mainly used for feeding purposes. Yield stability, effective weed suppression, and good quality of feed were reported as the best outcomes. The negative outcomes were complicated mechanical weed regulation, unequal maturation and additional costs for separation. The interviewed farmers showed predominantly positive prospects for the development of intercropping on their farms, problems with sowing techniques being the only importance [32].

Based on the statements in this chapter, we can once again underline the importance of the use of well-known [33] and new findings of beneficial intercropping effects on productivity and biodiversity in different farming systems [34] which is especially very important in changing climates [35]. Because the fact that intercropping is a more expensive and complicated cultivation than sole crop production, intercrops need wider support (like new research and simulation models) [36] that will be included in farming systems as a basic environmental measure at the field production level.

\section{Conclusions}

Based on the lack of environmental indicators which influence the functional biodiversity in the field, a precisely described importance of crop rotation, introduction of underutilized crops and intercrops, is given. Due to their many beneficial effects (crop rotation, nitrogen fixations by legumes instead of synthetic $\mathrm{N}$ fertilisers, weed suppression, yield stability, inter-specific complementarily, more efficient use of environmental sources, soil cover at under-sown crops, higher protein content in the seeds for grain feed or silage mixture, especially important after BSE crises), inter-cropping and underutilized crops represents a high valued strategy for long term biodiversity and sustainable plant production management. Because of the farmland intensification and complexity of biodiversity, intercropping and underutilized crops have been neglected in practice and only partly researched as a plant production system under different cultivation circumstances (sometimes site specific). More diverse crops and inter- 
cropping support a more stable ecosystem productivity, especially in the case of intercrops with legumes; here the inputs of artificial nitrogen can be significantly reduced. However, ecological intensification of agriculture depends on simple and clear ecologically oriented agro-environmental policies all over the world, which will not support "green washing " of conventional agriculture or »conventionalisation « of organic farming. Because of climate changes, the alternative field crops and intercrops need more political support and should be taken into account in EU CAP and OECD policies, which do not include suggested measures on national levels as part of environmental payments, not even outside Europe. Because of their importance, intercrops and alternative crops need to be a part of biodiversity indicators at field and landscape levels.

\section{Acknowledgements}

The idea for this paper came as part of the project 'CRP V4-1137 Alternative field crops in different production systems and crop rotations as a base for adaptation to climate changes and food supply with food and feed' supported by the Ministry of Education, Science and Sport and the Ministry of Agriculture and the Environment, for which we are thankful.

\section{Author details}

Franc Bavec ${ }^{*}$ and Martina Bavec

*Address all correspondence to: franci.bavec@um.si

University of Maribor, Faculty of Agriculture and Life Sciences, Hoce/Maribor, Slovenia

\section{References}

[1] AEP 2007-2013 - Agri-environmental payments, Ministry of Agriculture, Forestry and Food, Slovenia, Ljubljana, RDPRS, 2007: Rural Development Programme of the Republic Slovenia 2007-2013. Ministry of Agriculture, Forestry and Food, Ljubljana, 20.07.2007, 232 p.

[2] Greening CAP reform 2014-2020, and NAT/471, 2010-European Economic and Social Committee. 9 p. Available at (http://www.eesc.europa.eu/ressources/docs/ ces1178-2010_ac_en.doc) Accessed15.09. 2010.

[3] Liebman M., Helmers M. J., Schulte L. A., Chase C. A. Using biodiversity to link agricultural productivity with environmental quality: Results from three field experiments in Iowa. Renew. Agric. Food Syst. 2013;28115-128. 
[4] Yang J., Shi Z-F., Gao D., Liu L., Li C. Y. Mechanism on biodiversity managing crop diseases. Yichuan. 2012;34 1390-1398.

[5] Nicholls C. I., Altieri M. A. Plant biodiversity enhances bees and other insect pollinators in agro ecosystems. A review. Agron. Sust. development. 2013;33257-274.

[6] Jacobsen S. E., Sorensen M., Pedersen S. M., Weiner J. Feeding the world: genetically modified crops versus agricultural biodiversity. Agron. Sust. development. 2013;33 651-662.

[7] Bavec F., Bavec M. Organic production and use of alternative crops. Boca Raton, New York, London : Taylor \& Francis: CRC Press. 2006

[8] Williams J.T., Hag N. Global research on underutilized crops. An assesment of current activities and proposals for enhanced cooperation. ICUC.Sauthhampton, UK, 46 p. www.biodiversityinternational.org/Publications/, 2002; accessed 18.05.2014.

[9] Bavec F. Grobelnik Mlakar, S., Rozman, Č. Turinek, M., Bavec, M. How to create an efficient organic production and market for underutilized field crops : a review on the Slovenian case. In: JAENICKE, Hannah (ed.). Proceedings of the International Symposium on Underutilized Plants for Food Security, Nutrition, Income and Sustainable Development, Arusha, Tanzania, March 3-6, 2008, (Acta horticulturae 2009;806 443-449.

[10] Duke J., duCellier J. CRC handbook of alternative cash crops. Boca Raton: CRC Press. 1993

[11] Williams J.T. (ed.). Underutilised Crops: Cereals and Pseudocereals, London: Chapman \& Hall. 1995

[12] Belton P., Taylor J. (eds.). Pseudocereals and less common cereals. Springer-Verlag, Berlin, Germany. 2002.

[13] Ruiz K. B., Biondi S., Oses R., Acuna-Rodriguez I.S., Antognoni F., Martinez-Mosqueira E. A., Coulibaly A., Canahua-Murillo A., Pinto M., Zurita-Silva A., Zurita-Silva A., Bazile D. Jacobsen E.-S., Molina-Montenegro M. Quinoa biodiversity and sustainability for food security under climate change. A review. Agron. Sust. Development. 2014;34 349-359.

[14] Dixon J., Hellin J. Erestein O., Kosina P.U-imapct pathway for diagnosis and impact assessment of crop improvement. J. Agric. Sci. 2007;145195-206.

[15] Zuhair H. A. Pumpkin-seed oil modulates the effect of felodipine and captopril in spontaneously hypertensive rats. Pharmacol. Res. 2000;41 555-561.

[16] De Francischi M. L., Salgado J.M., Da Costa C.P. Immunological analysis of serum for buckwheat fed celiac patients. Plants. Foods Hum. Nutr. 1994;46 207-211.

[17] Li S. Q., Zhang Q.H. Advances in the development of functional foods from buckwheat. Crit. Rev. Food Sci. Nutr. 2001;41 451-459. 
[18] Krkoškova B., Mrazova Z. Prophylactic components of buckwheat. Food Res. Int. 2005;38 561-568.

[19] Rangarajan A., Chenoweth E. A., Kelly J. F., Age K. M. Iron bioavailability from amaranthus species: 2 Evaluation using haemoglobin repletition in anaemic rats. J. Sci. Food Agric. 1998;78 274-280.

[20] Prokopowicz D. Health promoting attributes of amaranths (Amaranthus cruentus). Met. Vet. 2001;57 559-561.

[21] Hauggaard-Nielsen H., Jørnsgaard H. Kinane J., Steen Jensen E. Grain legume-cereal intercropping: The practical application of diversity, competition and facilitation in arable and organic cropping system. Renewable Agriculture and Food Systems 2007;23 3-12.

[22] Bergkvist G. Stenberg M., Wetterlind J., Bath B., Elfstrand S. Clover cover crops under-sown in winter wheat increase yield of subsequent spring barley-Effect of $\mathrm{N}$ dose and companion grass. Field Crops Research.2011;120 292-298.

[23] Lithourgidis A. S., Vlachostergios D. N., Dordas C. A., Damalas C. A. Dry matter yield, nitrogen content, and competition in pea-cereal intercropping systems. Eu. Jour. Agron. 2011;34 278-294.

[24] Sun Y. M., Zhang N. N., Wang E. T., Yuan H. L., Yang J. S. and Chen W. X. Influence of intercropping and intercropping plus rhizobial inoculation on microbial activity and community composition in rhizosphere of alfalfa (Medicago sativa L.) and Siberian wild rye (Elymus sibiricus L.). FEMS microbiology ecology. 2009;7062-70.

[25] Shili-Touzi I., De Tourdonnet, S., Launay, M., Dore, T. (2011): Does intercropping winter wheat (Triticum aestivum) with red fescue (Festuca rubra) as a cover crop improve agronomic and environmental performance? A modeling approach Original Research Article. Field Crops. 2011;116218-229.

[26] Badgley C., Moghtader J., Quintero E., Zakem E., Chappell M.J., Aviles Vazquez K., Samulon A., Perfecto I. Organic Agriculture and the Global Food Supply. Renewable Agriculture and Food Systems 2007;22 86-108.

[27] Gebeyehu S., Simane B., Kirkby R. Genotype x cropping system interaction in climbing bean (Phaseolus vulgaris L.) grown as sole crop and in association with maize (Zea mays L.). Eur. J. Agron. 2006;24 396-403.

[28] Bavec F., Bavec M. Effect of plant population on leaf area index, cob characteristics and grain yield of early maturing maize cultivars (FAO 100-400). Eur. J. Agr. 2002;16 151-159.

[29] Kontturi M., Laine A., Niskanen M., Hurme T., Hyovela M., Peltonen-Sainio P. Peaoat intercrops to sustain lodging resistance and yield formation in northern European conditions Acta Agric. Scandinavica 2011;61612-621 
[30] Poggio S. L. Structure of weed communities occurring in monoculture and intercropping of field pea and barley. Agric. Ecosyst. \& Env. 2005;109 48-58.

[31] Li L., Tilman D., Lambers H., Zhang F. S. Plant diversity and over yielding: insights from belowground facilitation of intercropping in agriculture. New phytologist. 2014; 203 63-69.

[32] vonFragstein und Niemsdorff P., Knudsen D., Marie T., Gooding Mike J., Dibet A., Monti, M. Experiences with intercropping design - a survey about pulse cereal-combinations in Europe. Paper presented Jun 18-20 at ISOFAR 2008 in Modena, Italy.

[33] Willey R.W. Intercropping: its importance and research needs. Part 1. Competition and yield advantages. Field Crop Abstracts, Amsterdam, 1979;32 1-10.

[34] Bavec M., Grobelnik Mlakar S., Rozman Č., Pažek K., Bavec F. Sustainable agriculture based on integrated and organic guidelines: understanding terms : The case of Slovenian development and strategy. Outlook Agric.2009;38 89-95.

[35] Tsubo M., Walker S., Ogindo H. O. A simulation model of cereal-legume intercropping systems for semi-arid regions, II. Model application. Field crop research 2005;93 23-33.

[36] Baldy C., Stigter C.J. Agrometeorology of multiple cropping in Warming climates, INRA. 1997. 
